\title{
The experiences of people, with severe mental health conditions, participating in an Occupation Matters Programme: an interpretative phenomenological analysis.
}

\begin{abstract}
:
Introduction: The Occupation Matters Programme (OMP) is an Occupational Therapy intervention promoting recovery in people with severe mental health conditions, adapted from the Lifestyle Redesign (C) approach. With the increasing demand for mental health services and the UK's current financial position, there is cause to research the OMP.

Method: Interpretative phenomenological analysis provided a rich account of the experience of an $O M P$, eliciting the service user voice. Four participants participated in semi-structured interviews following session ten and at the completion of the twenty-week programme. Data analysis followed the step-by-step interpretative phenomenological analysis guidelines, enabling themes to be identified which reflected participants' experiences.

Findings: Three major themes were revealed: connecting with others; experiencing an opened-up world through a temporary project and finding a place in the world through a changing sense of self. Three participants described a temporary improvement in their mental health at halfway, which became more permanent by the completion of the programme.

Conclusions: This study suggests that the OMP was influential in the participants' recovery journeys and provides evidence for Wilcock's Doing, Being, Belonging and Becoming framework. It encourages occupational therapists to concentrate on occupation-centred practice, occupational integrity and implementing all four aspects of Wilcock's framework.
\end{abstract}

Key Words: Mental Health, Occupational Therapy, Occupation Matters Programme, Lifestyle Redesign (C, Doing, Being, Belonging and Becoming 


\section{Introduction}

The Occupation Matters Programme (OMP) is an occupational therapy intervention to promote recovery in people with severe mental health conditions. It has become established in Community Mental Health Recovery Teams in an NHS Trust over the last seven years. The intervention was adapted from the Lifestyle Redesign (C) approach to health and well-being in older adults (Clark, 2015) which is established in some parts of the United States. This paper presents research into four participants' experiences of the OMP, examines Wilcock's (2007) framework in transforming health and well-being and encourages the use of occupational integrity.

\section{Background}

Many drivers facilitated the development of the OMP, including: the Lifestyle Redesign (C) (Clark, 2015) and Lifestyle Matters (Mountain et al., 2017) literature; the promotion of occupation-centred practice (COT, 2015) and the developments within occupational science (Wilcock, 2007); and the increasing demand on recovery-orientated mental health services which integrate both physical and mental health care. These will each be considered in turn.

In some parts of the United States, Lifestyle Redesign (C) has become established as a clinical and cost-effective preventative occupational therapy intervention for independently-living older adults (Clark et al., 1997). This intervention consists of a weekly group, accompanied by monthly individual sessions, and focusses on healthy ageing, run by occupational therapists over a nine-month period (Clark et al., 1997). In the UK, an adapted version, Lifestyle Matters (Craig, 2009; Mountain et al., 2017), is now recommended for older people by the National Institute for Health and Care Excellence (2008).

The re-focussing of occupational therapy on its underlying philosophy; in which ill-health is examined from an occupational perspective (Taylor, 2017), was also key in developing the programme. The Royal College of Occupational Therapists (RCOT) has promoted occupationcentred practice and encouraged mental health services to meet people's occupational needs, assist in recovery journeys and prevent mental ill health (2015). Wilcock (2007) described the potential for transforming health and well-being through a dynamic combination of Doing, Being, Belonging and Becoming. Occupation-centred practice, 
promoting recovery and the developments in occupational science are at the heart of the OMP.

Lastly, recent drivers within mental health have also contributed towards the development of the OMP. In the United Kingdom (UK), the cost of mental health disorders amounts to $4.5 \%$ of Gross Domestic Product (McManus, 2016), with referrals to community mental health teams having risen by $20 \%$ over the past five years. It is estimated that two million more people will live with mental health disorders by 2030 than today (MIND, 2015). Added to this, mortality rates for people with mental health disorders are higher than those of the general population (McManus, 2016). This has all led to the OMP becoming a group intervention, outcome driven and integrating physical and mental health care by exploring the barriers that people, with mental health disorders, face in adopting healthier lifestyles.

Following these drivers, the first author established a project group of occupational therapists to adapt the Lifestyle Redesign (C) and Lifestyle Matters (Craig, 2009) interventions for working-age adults with severe mental health conditions, as there was no equivalent programme. Lifestyle Redesign (C) was mainly used by the project group rather than Lifestyle Matters, as it had a greater evidence base and more flexibility to adapt to this client group. This new OMP, comprising of twenty group and four individual sessions over a five-month period, explores the relationship between activities and mental health recovery. Participants then choose and engage in new or neglected activities, and re-design their lifestyles to facilitate recovery. 140 people have participated in 21 programmes within the Trust, each facilitated by two occupational therapists. A focus on: mental health, activities relating to a work role, and the careful grading of risk-taking activities for people with a severe illness are the main differences from Lifestyle Redesign $₫$, which focuses on a healthier older population. 


\section{Literature review}

Sixty-two studies were examined from a variety of databases along with grey literature. Search terms included 'Lifestyle Redesign,' 'Lifestyle Matters,' 'lifestyle approach' and 'mental health and occupational therapy' and the Critical Appraisal Skills Programme (Casp, 2018) was used to evaluate the papers.

\section{Lifestyle Redesign(C}

The original Well Elderly studies (Clark et al., 1997; Clark et al., 2001; Hay et al., 2002) used credible, well-powered randomised controlled trials to investigate the efficacy of Lifestyle Redesign $($. They found significant clinical and cost-effectiveness for Lifestyle Redesign $($ in enhancing the health and quality of life of independently-living older people. A later replicated study (Jackson and Clark, 2012), examined the effectiveness of a six-month Lifestyle Redesign (C) programme and found similar results, concluding that the intervention is feasible as a treatment in multi-ethnic community-based locations.

Lifestyle Redesign (C) is also used in the United States in weight-loss, pain management, student and executive health programmes, (Salles-Jordan, 2007). No literature was found discussing its use within the field of working-age mental health.

One randomised-controlled trial (Horowitz and Chang, 2004) found no significant results for Lifestyle Redesign (C) in chronic physical illness. The authors concluded that Lifestyle Redesign (C) should remain a preventative intervention, although they acknowledge their study was not well-powered. On closer examination, many principles of the intervention had been omitted and was therefore not a true Lifestyle Redesign (C) intervention. Further research, which includes all principles within the intervention and sufficiently powered, is required before suggesting that it is not suitable for people with severe illness.

A multi-centred, well-powered, randomised-controlled trial found no significant evidence for the clinical and cost-effectiveness of the UK's version, Lifestyle Matters (Mountain et al., 2017). The authors suggest that the sample in the Well Elderly studies scored lower for mental well-being at baseline than the sample in the Lifestyle Matters research, which may account for the findings. They therefore discussed the need to identify appropriate people at risk of mental and physical decline for the success of preventative lifestyle treatments. Other 
differences to Lifestyle Redesign (C) may also account for the findings, including nonoccupational therapists facilitating the programme, reducing the intervention to sixteen weeks, and having fewer individual sessions. There was no literature found discussing the use of Lifestyle Matters in the UK within mental health.

\section{Mental Health Occupational Therapy}

No mental health occupational therapy literature was found replicating the OMP or Lifestyle Redesign $@$ in working age adults. Lloyd and Samra (1996) discussed an eight-week group intervention, which appeared most similar to the OMP. Similarities included the topics addressed, giving choice to the participants and the occupation-centred focus. Their evaluation concluded that their lifestyle programme promoted life satisfaction. This presented an interesting opinion piece, however more research is needed to support the evaluation's claims. Differences existed between this intervention and the OMP, particularly the OMP's exploration of the relationship between activity and mental health recovery, and enabling participants to use this knowledge to redesign their own lifestyles.

\section{Purpose of the study}

The increasing demand for mental health services (MIND, 2015), combined with the UK government deficit of $£ 57.2$ billion drives the need to establish clinical and cost-effectiveness of occupational therapy interventions (Morley and Smyth, 2013). With this, and the gaps in literature on the use of Lifestyle Redesign (C) within mental health, there is cause to research the OMP.

Having established the OMP as a routine intervention in the Trust, service users reported finding it useful and this needed capturing more robustly through this research. This study intended to add the service user voice to the literature and understand the participants' experience of engaging in the programme. The following research question was therefore developed:

"What are the experiences of people, with a severe mental health condition, participating in an Occupation Matters Programme?" 


\section{Method}

\section{Methodology:}

Interpretative Phenomenological Analysis (IPA) (Smith et al., 2009) was identified as the most appropriate methodology, as it undertakes a deep, systematic exploration of the meaning of an experience. IPA does not seek to establish broad generalisable knowledge of a population (Smith et al., 2009), instead, this study provides an insightful account of an interpretation of four participants' experiences of one OMP.

\section{Research Population and Recruitment}

A purposive sampling approach was used to recruit four participants attending one OMP in one community team. This is supported by Smith et al. (2009), who recommend small sample sizes in IPA studies due to the focus on a detailed understanding of an individual's experience.

The inclusion/exclusion criteria (Table 1 ) was applied to all group members, by the occupational therapists facilitating the group. To reduce coercion, care coordinators gave the information sheet to potential participants, which included a reply slip to express interest. The researcher then contacted those who returned the slip and sought consent from those potential participants. Two males and two females provided written informed consent to participate. 


\begin{tabular}{|c|c|}
\hline Inclusion Criteria & Exclusion Criteria \\
\hline $\begin{array}{l}\text { - Aged } 18-65 \text { as there is currently a } \\
\text { specific programme for people over this } \\
\text { age. }\end{array}$ & $\begin{array}{l}\text { - People in receipt of another form of } \\
\text { mental health therapy. }\end{array}$ \\
\hline $\begin{array}{l}\text { - People with a mental health diagnosis } \\
\text { who were commencing an OMP in } \\
\text { January } 2017 \text {. }\end{array}$ & $\begin{array}{l}\text { - People who have planned changes to } \\
\text { their medication during the OMP }\end{array}$ \\
\hline $\begin{array}{l}\text { - People with a stable mental state at the } \\
\text { time of recruitment as assessed by the } \\
\text { occupational therapists running the } \\
\text { OMP, based on a brief mental state } \\
\text { examination. }\end{array}$ & $\begin{array}{l}\text { - People detained under the Mental } \\
\text { Health Act (2007), following a } \\
\text { recommendation from the NHS Ethics } \\
\text { Committee due to concerns over } \\
\text { coercion. }\end{array}$ \\
\hline $\begin{array}{l}\text { - People with the mental capacity for } \\
\text { decision making in regard to } \\
\text { participating in this research project, } \\
\text { based on the principles of the Mental } \\
\text { Capacity Act (2005). }\end{array}$ & $\begin{array}{l}\text { - People who were unable to understand } \\
\text { verbal explanations, written information } \\
\text { in English, or had special communication } \\
\text { needs. This was because an in-depth } \\
\text { account of the phenomenon was } \\
\text { required and this is a piece of student } \\
\text { research with limited time, funding and } \\
\text { resources. }\end{array}$ \\
\hline
\end{tabular}

Table 1: Inclusion/Exclusion Criteria 


\section{Ethical Considerations}

Ethical approval was gained from the Health Research Authority, the NHS Research Ethics Committee, the Trust's Research and Development Department and the University.

The study was located within the NHS Trust where the researcher is employed and leads the development of the OMP. To reduce the researcher's influence on the study, the researcher had not worked in the community team, did not know the research participants and did not facilitate the OMP. As suggested by Etherington (2004), the researcher used reflexive journals and supervision to engage with their own subjectivity and influence upon the study.

\section{Data collection:}

Semi-structured interviews, digitally recorded for transcription purposes, were carried out following session ten and on completion of the OMP (week 20). The first interview schedule (Table 2) focused on participant's initial experiences of the programme, whereas the second was adapted to focus on their experiences as a whole. These resulted in eight, sixty-minute interviews, permitting in-depth discussions of participants' experiences over the duration of the programme. The interviews were open, avoided making assumptions or lead to particular answers, and allowed participants to discuss what was meaningful for them. 


\begin{tabular}{|c|c|}
\hline Interview Schedule 1 & Interview Schedule 2 \\
\hline $\begin{array}{l}\text { Can you tell me about how you came to be } \\
\text { doing the programme? } \\
\text { - How did you feel/think about doing the } \\
\text { programme? } \\
\text { - What made you want to join the group? } \\
\text { - Why did you chose to join it? }\end{array}$ & $\begin{array}{l}\text { Can you tell me about your whole experience of } \\
\text { the programme? }\end{array}$ \\
\hline $\begin{array}{l}\text { What did you expect the programme to be like? } \\
\text { - What was the source of these } \\
\text { expectations? } \\
\text { - How has it lived up to/not lived up to these } \\
\text { expectations? }\end{array}$ & $\begin{array}{l}\text { Can you tell me about the things you remember } \\
\text { that you've done on the programme? }\end{array}$ \\
\hline $\begin{array}{l}\text { What was it like for you when you joined the } \\
\text { programme? } \\
\text { - Tell me about the } 1^{\text {st }} \text { session, what was that } \\
\text { like? }\end{array}$ & $\begin{array}{l}\text { Can you describe a session/activity that has } \\
\text { been important to you/ really good/ } \\
\text { helpful/useful/likeable/enjoyable (their } \\
\text { words)?? } \\
\text { - What was it that made it important/good? } \\
\text { helpful/useful/likeable/enjoyable (their } \\
\text { words)? }\end{array}$ \\
\hline $\begin{array}{l}\text { Can you tell me about the things you remember } \\
\text { that you've done on the programme so far? }\end{array}$ & $\begin{array}{l}\text { Can you describe a session/activity that has } \\
\text { been hard? } \\
\text { - What was it that made it hard? } \\
\text { - What was it that made it less } \\
\quad \text { useful/likeable (their words)? }\end{array}$ \\
\hline $\begin{array}{l}\text { Can you describe a session/activity that has } \\
\text { been important to you/ really good? } \\
\text { - What was it that made it important/good? } \\
\text { - What was it that made it } \\
\text { /helpful/useful/likeable/enjoyable (their } \\
\text { words)? }\end{array}$ & $\begin{array}{l}\text { Can you tell me what this experience has meant } \\
\text { to you so far? }\end{array}$ \\
\hline $\begin{array}{l}\text { Can you describe a session/activity that has } \\
\text { been hard/difficult/ didn't like? } \\
\text { - What was it that made it hard? } \\
\text { - What was it that made it less } \\
\text { useful/likeable (their words)? }\end{array}$ & $\begin{array}{l}\text { Can you tell me about any changes that have } \\
\text { occurred for you over the time of the } \\
\text { programme? }\end{array}$ \\
\hline $\begin{array}{l}\text { Can you tell me about your experience of the } \\
\text { programme so far? } \\
\text { - What's it been like so far? }\end{array}$ & $\begin{array}{l}\text { How do you think things would be different if } \\
\text { you had not started the programme? }\end{array}$ \\
\hline $\begin{array}{l}\text { Can you tell me what this experience has meant } \\
\text { to you so far? }\end{array}$ & $\begin{array}{l}\text { Can you tell me about your experience of the } \\
\text { programme outside of the group sessions? } \\
\text { - How has your experience of the } \\
\text { programme fitted with the rest of your life? } \\
\text { - Has this experience had any impact on the } \\
\text { rest of your life? }\end{array}$ \\
\hline
\end{tabular}




\begin{tabular}{|c|c|}
\hline $\begin{array}{l}\text { Tell me about your experience of the } \\
\text { programme outside of the group sessions? } \\
\text { - How has your experience of the } \\
\text { programme fitted with the rest of your life? } \\
\text { - Has this experience had any impact on the } \\
\text { rest of your life? }\end{array}$ & $\begin{array}{l}\text { What do you think others who know you well, } \\
\text { would think about your experience of the } \\
\text { whole programme? }\end{array}$ \\
\hline $\begin{array}{l}\text { Tell me about some other things about this } \\
\text { programme? }\end{array}$ & $\begin{array}{l}\text { Tell me about anything else regarding this } \\
\text { programme? }\end{array}$ \\
\hline \multicolumn{2}{|c|}{ Prompts to use with all questions to encourage the participant to expand further: } \\
\hline $\begin{array}{l}\text { What happened? } \\
\text { Can you tell me more about... } \\
\text { What did you think... } \\
\text { How did you cope with ... } \\
\text { How? } \\
\text { Tell me what you were feeling... } \\
\text { I'm really interested to hear more about... }\end{array}$ & $\begin{array}{l}\text { Can you give me an example of ... } \\
\text { How did you feel.... } \\
\text { How did you manage .... } \\
\text { Why? } \\
\text { Tell me what you were thinking ... } \\
\text { This might seem a stupid question, but, why is ... } \\
\text { What do you mean by ..... }\end{array}$ \\
\hline
\end{tabular}

Table 2: Interview schedule 1/2

\section{Data Analysis:}

The interviews were transcribed by the researcher/author, password protected and used pseudonyms. The recordings were then deleted. Following this, Smith's (2011) guidelines for analysis were followed.

\section{i. Step-By-Step Analysis:}

The analysis involved first making initial notes, followed by repeated readings of the data and deeper, exploratory notes. These were analysed to identify emergent themes and superordinate categories. These steps were repeated with subsequent participants and finally, patterns, connections and differences across the cases were identified.

\section{ii. Levels of Interpretation:}

Within each step, different levels of interpretation were used to explore the accounts for social comparisons, metaphors, a micro-analysis of the text and the continual use of the hermeneutic circle. The hermeneutic circle involved continually moving between examining micro aspects of the text, including specific word usage, temporal aspects and the tenses used, to the macro aspects, enabling interpretations of hidden meanings beneath the words. 


\section{Rigour}

To ensure this was a robust study, the four principles described by Yardley (2000) and Smith's (2011) evaluation guide were considered. This included applying a thorough, auditable, transparent, rigour to the research and moving from description to an interpretation of the meaning of the experiences. It included building empathy, awareness of dynamics between participant and researcher and showing a sensitivity by using substantial excerpts from the data. To ensure this study was not subject to the common critiques of phenomenological research within healthcare (Pringle, 2011), Finlay's (2011) six facets of the phenomenological task were also considered. This involved paying attention to the phenomenological attitude by putting aside previous beliefs and assumptions to elicit rich accounts of the meaning of the experiences. There was also a focus on existential concerns, connections between the body, self and world and the potential for growth in the participants through the research. 


\section{Findings}

Participants' characteristics are presented in Table 3.

\begin{tabular}{|l|c|l|c|c|c|}
\hline Pseudonym & Gender & Age & Diagnosis & $\begin{array}{c}\text { Length of } \\
\text { diagnosis }\end{array}$ & $\begin{array}{c}\text { Living } \\
\text { circumstances }\end{array}$ \\
\hline Andrew & M & 31 & $\begin{array}{c}\text { Depression } \\
\text { Avoidant personality disorder }\end{array}$ & $\begin{array}{c}\text { Since } \\
\text { childhood }\end{array}$ & With parents \\
\hline Sally & F & 44 & $\begin{array}{c}\text { Depression } \\
\text { Eating disorder } \\
\text { Borderline personality disorder }\end{array}$ & $\begin{array}{c}\text { Since } \\
\text { childhood }\end{array}$ & Alone \\
\hline Anne & F & 54 & $\begin{array}{c}\text { Depression } \\
\text { Avoidant personality disorder }\end{array}$ & Since teens & With husband \\
\hline Stephan & M & 38 & Bipolar Disorder & Since teens & With partner \\
\hline
\end{tabular}

Table 3: Characteristics of sample

\section{Overview of findings}

The themes that emerged from the study are presented in Table 4. To ensure findings are grounded in participants' experiences, verbatim quotations using pseudonyms are used, followed by a number, identifying which interview gathered the data.

\begin{tabular}{|c|c|}
\hline Theme & Sub-theme \\
\hline 1. Connecting with others & $\begin{array}{l}\text { 1a Loss of connection to others } \\
\text { 1b Transition from isolation to a sense of } \\
\text { belonging }\end{array}$ \\
\hline $\begin{array}{l}\text { 2. Experiencing an opened up world } \\
\text { through a temporary project }\end{array}$ & $\begin{array}{l}\text { 2.a "You can't learn to surf on a flat lake" } \\
\text { 2.b The group as a temporary project }\end{array}$ \\
\hline $\begin{array}{l}\text { 3. Finding a place in the world through a } \\
\text { changing sense of self }\end{array}$ & $\begin{array}{l}\text { 3.a "More like human beings again, rather } \\
\text { than just ghosts" } \\
\text { 3.b The battle to change }\end{array}$ \\
\hline
\end{tabular}

Table 4: Themes and sub-themes from the data analysis 


\section{1: Connecting with others}

All participants powerfully described a transition from feeling isolated to a sense of belonging and connection to the world.

\section{Sub-theme 1a: Loss of connection to others}

At the beginning of the programme, feelings of isolation and a loss of connection to others, resulted from their mental health. They described being a stranger in the world, alienated from those around them, unable to express their feelings due to the invisibility of their condition, and living in a world which lacks understanding of mental health or even denies its existence:

"if I said that I felt a certain way...they [family] wouldn't acknowledge it...they just don't understand mental health at all... because you can't touch it, you can't feel it"(Sally1).

This inability to express feelings led the participants to discuss an inauthentic persona they showed to the world; hiding for fear of how they might be perceived. They discussed having an 'outside' face, representing themselves as 'coping,' in contrast to the emotional turmoil they felt internally:

"I feel the stress, but I feel stressed that I shouldn't look stressed, inside I'm actually dying" (Anne1).

This need to portray a 'coping' face led participants to feel they had to deal with difficulties alone, increasing their isolation and alienation from the world:

"I don't say anything to my family and friends, so I feel incredibly isolated...I don't tell anyone, I feel I have to face it alone"(Anne1).

\section{Sub-theme 1b: The transition from isolation to a sense of belonging}

As the programme progressed, a deep sense of belonging emerged. Participants' language changed from discussing ' $I$ ' and 'they' when referring to themselves or other participants, to 'we' and 'us.' Deeper connections developed as they shared feelings about mental health, the difficulties they faced, recognised they were not alone and were similar to others:

"I forced myself to be open...I didn't want to hide anything...I gave it 100\%...I surrendered" (Stephan2). 
"you realise there are a lot of other people who are in the same boat...professional support is not the same or even other friends, it's the knowledge that you're going to be understood like really empathetically and that you're not going to be given platitudes" (Andrew1).

This revealed a more authentic self, rather than the inauthentic persona, leading participants to feel understood, not judged, and accepted for who they were:

"what I said in the group [having self-harmed], no one threw their hands up in the air and said how terrible ...no-one actually judges you for thinking in a certain way"(Sally1).

"It's nice to know that, when you've isolated yourself...knowing that you...can still be accepted by the group...There's some form of deeper connection"(Andrew1).

In contrast, one participant Anne, had difficulty in revealing this more authentic self. She frequently adopted her familiar role of a 'carer,' where she would hide her feelings behind an inauthentic capable persona, protecting herself from her own too powerful, overwhelming feelings:

"I don't really say in the group how I'm feeling. I just find it really difficult to say... I'm like back to being a carer again... I transfer that on to helping others because then it takes away the focus from myself"(Anne1). 


\section{2: Experiencing an opened up world through a temporary project}

At the beginning, the participants described a closed, controlled, friendless world which they created in an attempt to eliminate anxiety or depression. As the programme progressed, a larger world opened up for the participants, as it changed from an anxiety-filled space at the beginning to a safe place to take risks and engage in new activities.

\section{Sub-theme 2a: "You can't learn to surf on a flat lake"}

This metaphor describes the risks all participants discussed and their courage in using the programme to face anxieties and open-up their closed, controlled worlds; something they believed necessary for recovery.

"You can't learn to surf on a flat lake... You can't put yourself in a sterilised setting and expect to be able to deal with life after a period of time"(Andrew1).

At the beginning of the programme they described extreme anxiety in attending the group: "It was terribly, terribly stressful for me... the first week was terrible... they all put another weight on top of me"(Stephan1).

As the programme progressed, an increased sense of belonging, peer support and encouragement meant the group became a safe place to take risks in engaging in activities they had felt incapable of doing:

"It makes you less concerned of trying things because you're less concerned about having to cope with the potential consequences on your own ... there is the support where if stuff does go wrong, you know, there's not so much of a worry"(Andrew1).

"I felt like I could trust the group by the end...it wasn't easy...it was risky, it was a safe group to take a risk"(Sally2).

\section{Sub-theme $\mathbf{2 b}$ : The programme as a temporary project}

The programme became a 'temporary project' for the participants, a collaborative enterprise of meaningful activities which they chose and carefully planned how to achieve. The project offered experiences of success when they achieved activities they had previously felt 
incapable of doing; and a sense of purpose as they chose activities that were important to them:

"I did it [going on a bus], and I did it on the way back as well, we achieved something.

We all achieved it...like a...collective victory!...the facts are that I hadn't been on a bus for two years. It is a big achievement"(Sally1).

"Now I feel better, I feel better because I accomplished some things"(Stephan2).

The participants developed a sense of meaning, identity, a reason to exist and their worlds' began to open up as they engaged in new activities outside the group:

"it is important to accomplish something...there's always some reason we're in this world... I'm a photographer, I'm a graphic designer...the programme has given me reason to go out"(Stephan1).

Anne's experience of the activities was different to others. They became a distraction, something to hide herself behind, avoiding her own, and other's emotions:

"I think it's better when the focus is on the activity rather than yourself...। think it's just best in the group when we're given a task to do because I feel we all flounder a bit if we don't have something to focus on"(Anne2).

\section{3: Finding a place in the world through a changing sense of self}

Participants described a different 'way of being,' and unlocked the possibility of a future self, different from the self at the beginning of the programme. This involved feeling more 'normal', a whole human being; connected to the world.

\section{Sub-theme 3a: "More like human beings again, rather than just ghosts"}

Early in the programme, all described an 'ill' self: alone, isolated and incapable of many activities due to overwhelming anxiety or depression. Participants experienced being different and unequal to others, or even not existing. The term 'normal' was used to discuss other people without mental health conditions, disclosing their sense of being 'abnormal' and different from others: 
"It would be good to do it [go on the bus regularly], as that's what normal people do... I have always wanted to be invisible ... probably why I got an eating disorder all those years ago"(Sally1).

The participants experienced a different way of 'being,' involving a sense of hope, equality, empowerment, responsibility and control over their lives. By the end of the programme, this led to a more 'normal' self, of becoming more visible; finding a place in the world and being part of society again. They saw themselves as whole people, seeing their abilities rather than just their disabilities:

"We were just getting more like human beings again, rather than just ghosts or not there people" (Stephan2).

"I like the way it's governed by what the group wants to do... I've been powerless in a lot of situations in my life, it feels like we are being encouraged to take a bit of that power back... I think it's very healing being treated as an equal... I think maybe I'm not that abnormal"(Sally2).

"It's not all about the illness, we get to know each other as human beings... they saw you as an individual"(Anne2).

This shift in self led three participants to describe an improvement in their mood. Stephan had described his mood as close to despair and suicidal. However, by halfway his mood had improved temporarily and, by the end, he discussed a more permanent improvement:

"[At the beginning] I'm really down at the bottom of the ground, I can't go any more down, just want to put my nails in the soil and lift myself up. I was deadly quiet and silent...I wasn't talking to my partner...I was talking to myself...giving me a command to end my life"(Stephan1).

"it [the programme] gives me euphoria today... lifts my mood, it clears the grey cloud from my mind ... then Thursday, oh what a hollow... I hate going back to the dark room in my mind,"(Stephan1). 
"The group, now I'm happy, I'm happy now all the time"(Stephan2).

Anne felt less change in her sense of self, less of the normalising effect and no improvement in her mood, although she did describe benefits from the programme. These benefits appeared more concrete: things she could do, rather than a change in her inner self. Her inability to share her feelings meant that she was not able to be vulnerable and take risks and remained hidden behind her capable persona.

"You learn quite a lot... about how they cope with things, which you can use ... I got a lot out of listening to other people's coping strategies and what they were doing"(Anne2).

\section{Sub-theme 3b: The battle to change}

This new way of 'being' was a difficult, ambivalent place to be, and two participants discussed surrendering to their old ways of being at times. The words "new" and "novel" were used repeatedly throughout the second interviews in relation to this change, revealing an unfamiliar sense of being:

"It feels very new... it is very novel... It sounds really alien for me... it's a bit strange really, it's good, but it's hard to hold on to, when I've got my family's saying one thing and the group saying another"(Sally2).

The tranquillity in Andrew's use of the 'flat lake' metaphor may also be significant. This perhaps symbolises his temptation to remain on a peaceful lake and the difficulties involved in facing the waves. 


\section{Discussion}

\section{Doing, Being, Belonging and Becoming}

Hammell (2014) suggested that Wilcock's (2007) framework for transforming health and wellbeing through Doing, Being, Belonging and Becoming is essentially theoretical, with Kosma, Bryant and Wilson (2013) encouraging a need to generate evidence for these concepts. It was the synthesis of these four elements of Doing, Being, Belonging and Becoming, which appeared to promote health and well-being in this study.

The OMP focussed on Doing, where the group engaged in meaningful activities, which made it different to the participants' previously-attended, talking-based therapy groups. Through this Doing, participants were encouraged to $\mathrm{Be}$, to discuss feelings, the challenges they faced, their abilities and their strengths. This Being also entailed giving the participants choice to ensure activities reflected their values and were meaningful. This provided an opportunity to express who they were and be vulnerable at times; rather than the persona they usually assumed. Daniel (1998) suggested that authenticity is encouraged when people show their vulnerability, and when authentic, a sense of empowerment develops. A sense of empowerment developed in this study as the participants became more authentic through the doing of activities.

As this more authentic self was expressed and accepted by the group, a strong sense of Belonging emerged. Bledin (2016) described a sense of belonging within a group is fundamental to the recovery of people who experience prolonged social isolation. Kimiko (2018) suggested that people with mental health conditions have a greater sense of empowerment when belonging to a community. As this Being and Belonging developed in the OMP, the Doing element increased, as participants felt safe to take risks to do activities they had previously felt unable to do. This facilitated a sense of achievement, success, purpose, and identity. This sense of Doing, Being and Belonging, in turn led to the Becoming element; becoming more 'normal' and a 'whole' person, not just an illness. Participants experienced a transformation in their way of being, becoming more authentic, capable of achieving things and experienced an improvement in their mental health. This therefore provides an example of, and evidence for, the application of Wilcock's framework of Doing, Being, Belonging and Becoming in occupational therapy. 
Hayward and Taylor (2011) discussed occupational therapy's emphasis on Doing at the expense of Being, as the profession has concentrated on occupational performance. Hammell (2014) suggested that occupational therapy models have promoted this emphasis by categorising Doing as self-care, productivity and leisure, and they particularly discuss the neglect of Belonging within occupational therapy. Blank (2016) also asserts that there is a neglect of Belonging and concludes that the Doing may not be as significant in occupational therapy as previously believed. This study does not support this assertion, as the Doing of activities encouraged a sense of Being and Belonging. It was this combination which led to their powerful, collective victories and facilitated the Becoming, leading to a sense of health and well-being. This study therefore supports Hammell (2014) and Hayward and Taylor (2014), and the importance of all four aspects of Wilcock's framework.

\section{Improved Mental Health, Well-Being and Authenticity}

Three participants discussed an improvement in their mood as the programme continued. Psychology literature discusses a hedonistic well-being: equating to pleasure and happiness, and a eudaimonic well-being: which occurs when our activities fit our values, creating a more authentic existence (Leary and Tangney, 2003). Occupational therapy literature encourages the use of interventions which provide occupational integrity (Pentland and McColl, 2008). Occupational integrity occurs when interventions in occupational therapy fit the values, identity and purpose of the person and design lifestyles which are congruent with these. Hayward \& Taylor (2011) suggest that the experience of occupational integrity produces a sense of eudaimonic well-being.

Both hedonistic and eudaimonic well-being were described by three participants in this study. They discussed elements of occupational integrity within the OMP including a sense of meaning, choice, empowerment and expressing a more authentic self which perhaps created a sense of eudaimonic well-being and the improvement in mental health. This therefore supports Hayward and Taylor's (2011) findings and encourages occupational therapists to facilitate occupational integrity to promote eudaimonic well-being.

Phenomenology has long recognised the concept of authenticity, with Heidegger differentiating between an authentic and inauthentic mode of being (Moran, 2000). Sartre suggested that, because life is meaningless, we need to confront our anxiety and live 
authentically. This involves people finding their own meaning in the world by involving themselves in projects which fits with who they are (Moran, 2000). Sartre recognised inauthenticity as hiding from anxiety, assuming a persona and living a life which is not true to who we are (Moran, 2000). At the beginning of the programme, all the participants discussed an isolation from the world. They assumed an inauthentic persona, having few authentic moments, and this continued to increase their isolation. As the programme continued, three participants were able to describe a more authentic self at times, a self which, on occasions, was able to put their 'front' aside, be vulnerable, face their feelings and surrender to the difficulties and challenges they encountered.

One participant, however, felt less able to show her feelings, was less vulnerable and remained hidden behind her inauthentic persona of a 'capable carer'. This difficulty in experiencing the Being aspect of Wilcock's framework meant she maintained her inauthentic persona, did not experience acceptance of a more authentic self, could not belong as much to the group and did not experience the Becoming and sense of well-being that others described. This finding suggests the importance of this Being aspect, in enabling authenticity and its involvement in creating a sense of well-being. It calls for occupational therapists to use the Doing to facilitate the Being within Wilcock's framework. This involves occupational therapists encouraging clients to discuss feelings, show vulnerability at times and carefully explore their defence mechanisms, while being mindful that adopting a persona can be essential in surviving emotional pain (Blank et al., 2016).

\section{Limitations}

The small sample size is a limitation in this study. However, IPA studies focus on small, homogenous samples, where depth of understanding takes precedence over large generalisable data. If more time had been available, a larger sample may have allowed other similarities and differences between participants to emerge, and consideration of transferability may have been stronger. The sample was recruited from one locality in one NHS Trust which may reflect a unique viewpoint. Different programmes, facilitated by different therapists may have also yielded additional findings and again increased transferability. Future research in different geographical locations could therefore be compared. Future quantitative research is also necessary to ascertain clinical and cost- 
effectiveness which can be generalised to the population of people with severe mental health conditions.

\section{Conclusion}

This interpretative phenomenological analysis suggests that this OMP was influential in the participants' recovery and for three of them, it appeared to offer a more authentic existence, improved their mood and a sense of hedonistic and eudaimonic well-being. The use of Wilcock's framework of Doing, Being, Belonging and Becoming encouraged involvement in a temporary project of meaningful activities and facilitated deeper connections between participants. They felt more connected to the world and discarded part of their 'ill' self, seeing themselves as more 'normal,' whole people, rather than as an illness and, although difficult at times, they experienced a new, more authentic way of being. One participant, who was less able to put aside her persona, made fewer changes than the others. This study encourages the use of occupation-centred practice and the use of the Doing aspect of Wilcock's framework to facilitate a sense of Being, Belonging and Becoming and for educators to consider this in their curriculum. This study supports the adaptation of the Lifestyle Redesign (C) intervention for these four participants, provides evidence for Wilcock's framework of Doing, Being, Belonging, and Becoming and encourages occupational therapists to facilitate occupational integrity. 


\section{Key Findings:}

- An Occupation Matters Programme, adapted from Lifestyle Redesign@, facilitated participants' mental health recovery.

- The 'Doing' created a temporary project which facilitated 'Being, Belonging and Becoming' in Wilcock's framework.

- The 'Being' including occupational integrity appeared instrumental in creating well-being.

\section{What the study has added:}

An interpretative phenomenological analysis of the experience of an OMP, adding the service users' voice to the literature on an adapted version of Lifestyle Redesign ( for people with severe mental health conditions. 


\section{References}

Blank A, Finlay L and Prior S (2016) The lived experience of people with mental health and substance misuse problems: Dimensions of belonging. British Journal of Occupational Therapy 79 (7): 434-441.

Bledin K, Loat M and Caffrey A et al. (2016) Most Important Events' and Therapeutic Factors: An Evaluation of Inpatient Groups for People with Severe and Enduring Mental Health Difficulties. Group Analysis 49 (4): 398-413

Better Value Healthcare. 2018. Critical appraisal skills programme. Available from: http://www.caspuk.net/casp-tools-checklists]

Clark F, Blanchard J, Sleight A et al., (2015) Lifestyle redesign: The intervention tested in the usc well elderly studies. Vol. 2nd Edition. United States of America: The American Occupational Therapy Association, Inc.

Clark, F., S.P. Azen, M. Carlson, D. Mandel, L. LaBree, J. Hay, R. Zemke, J. Jackson, and L. Lipson. 2001. Embedding health-promoting changes into the daily lives of independent-living older adults: Long-term follow-up of occupational therapy intervention. The journals of gerontology.Series $B$, Psychological sciences and social sciences 56 (1): P60.

Clark, F., S.P. Azen, R. Zemke, J. Jackson, M. Carlson, D. Mandel, J. Hay, K. Josephson, B. Cherry, C. Hessel, J. Palmer, and L. Lipson. 1997. Occupational therapy for independent-living older adults. A randomized controlled trial. JAMA 278 (16): 1321.

College of Occupational Therapists (2015) Essential briefing: Occupational-centred practice. Available at www.rcot.co.uk/practice-resources/occupational-therapy-topics/scope-practice

Craig, C., Mountain, Gail. 2009. Lifestyle matters: An occupational approach to healthy ageing. United Kingdom: Speechmark.

Daniel L (1998) Vulnerability as a key to authenticity. Journal of Nursing Scholarship 30(2): 191 - 192

Etherington K. (2004) Becoming a Reflexive Researcher, Using our selves in research. London: Kingsley.

Finlay L and Dawsonera. (2011) Phenomenology for therapists: Researching the lived world. Vol. 1. Chichester: Wiley-Blackwell.

Hammell K (2014) Belonging, occupation, and human well-being: An exploration. Canadian Journal of Occupational Therapy-revue canadienne d ergotherapie 81 (1): 39-50.

Hayward C and Taylor J (2011) Eudaimonic well-being: Its importance and relevance to occupational therapy for humanity. Occupational Therapy International 18 (3): 133-141.

Hay, J., L. LaBree, R. Luo, F. Clark, M. Carlson, D. Mandel, R. Zemke, J. Jackson, and S.P. Azen. 2002. Cost-effectiveness of preventive occupational therapy for independent-living older adults. Journal of the American Geriatrics Society 50 (8): 1381-1388.

Horowitz B and Chang P (2004) Promoting well-being and engagement in life through occupational therapy lifestyle redesign: A pilot study within adult day programs. Topics in Geriatric Rehabilitation $20(1): 46$. 
Jackson J and Clark F (2012) The effectiveness of lifestyle redesign: Results of the well elderly 2 study. British Journal of Occupational Therapy 75: 27-28.

Kimiko T, Davidson L and Craig T (2018) Sense of clubhouse community belonging and empowerment. International Journal of Social Psychiatry 64(3) 276-285

Kosma A, Bryant W and Wilson L (2013) Drawing on Wilcock: An investigation of the impact of her published work on occupational therapy practice and research. The British Journal of Occupational Therapy 76 (4): 179-185.

Leary M and Tangney J (2003) Handbook of self and identity. New York: The Guilford Press.

Lloyd C and Samra P (1996) Healthy lifestyles: A community programme for chronically mentally ill people. The British Journal of Occupational Therapy 59 (1): 27-32.

McManus S, Jenkins R and Brugha T (2016) Mental health and wellbeing in england: Adult psychiatric morbidity survey 2014. Available at www.content.digital.nhs.uk/catalogue/PUB21748/apms-2014exec-summary

MIND (2015) A manifesto for better mental health - general election 2015, United Kingdom. The Mental Health Policy Group. Available at www.mind.org.uk/media/1113989/a-manifesto-for-bettermental-health.pdf [

Moran D (2000) Introduction to phenomenology. New York: Routledge.

Morley M and Smyth G (2013) Are occupational therapy interventions for service users with mental health problems cost-effective? The British Journal of Occupational Therapy 76 (10): 470-473.

Mountain G, Windle $G$ and Hind D et al. (2017) A preventative lifestyle intervention for older adults (lifestyle matters): A randomised controlled trial. Age and Ageing 46 (4): 627-634.

National Institutue for Health and Care Excellence (2008) Mental wellbeing in over 65s: Occupational therapy and physical activity interventions, United Kingdom: National Institute for Health and Care Excellence [Online]. Available from:https://www.nice.org.uk/guidance/PH16 [

Pentland W and McColl M (2008) Occupational integrity: Another perspective on "Life balance". Canadian Journal of Occupational Therapy 75 (3): 135-138.

Pringle J, Hendry C and McLafferty (2011) Phenomenological approaches: Challenges and Choices. Nurse Researcher. 18(2): 7

Salles-Jordan K (2007) Community health promotion programs using usc lifestyle redesign. Home and Community Health Special Interest Section Quarterly 14 (2): 1-4.

Smith J (2011) Evaluating the contribution of interpretative phenomenological analysis: A reply to the commentaries and further development of criteria. Health Psychology Review 5 (1): 55-61.

Smith J, Larkin M and Flowers P (2009) Interpretative phenomenological analysis: Theory, method and research. London: SAGE.

Taylor R (2017) Kielhofner's model of human occupation. version 5. China: Wolters Kluwer. 
Vos T, Barber R and Bell B et al., (2015) Global Burden of Disease Study: Global, regional, and national incidence, prevalence, and years lived with disability for 301 acute and chronic diseases and injuries in 188 countries, 1990-2013: A systematic analysis for the global burden of disease study 2013. The Lancet 386 (9995): 743-800.

Wilcock A (2007) Occupation and health: Are they one and the same? Journal of Occupational Science 14 (1): 3-8.

Yardley L (2000) Dilemmas in qualitative health research. Psychology \& Health 15 (2): 215-228. 